\title{
Parent-Mediated Toilet Training for a Child with Autism Spectrum Disorder through Teleconsultation: A Case Report
}

\author{
Hisashi Ito* and Masahiko Inoue $\dagger$ \\ *I's Support, Nagoya 466-0041, Japan, and †Department of Clinical Psychology, Graduate School of Medical Sciences, Tottori \\ University, Yonago 683-8503, Japan
}

\begin{abstract}
In defecation training, parent-mediated intervention via teleconsultation is helpful because the number of instructions for establishing defecation habits is limited. In the case report of the present study, defecation training was conducted based on gradual target setting and differential reinforcement through teleconsultation via email for a Caucasian 5-year-old boy with autism spectrum disorder (ASD) who lived in Greece. As a result of the intervention, namely the gradual target setting and differential reinforcement, in-bowl defecations increased at home.
\end{abstract}

Key words autism spectrum disorder; consultation; defecation; toilet training

Toilet training is crucial for the quality of life of individuals with autism spectrum disorder (ASD) and other developmental disabilities. Children with ASD tend to have more toileting problems than the normal population. ${ }^{1}$ Toilet training is divided into urination and defecation. Defecation training has certain difficulties due to the following causes: infrequency, less frequency with constipation, difficulty in learning due to intellectual disability, ritual patterns due to unique sensations, difficulty in movement and posture, noncompliance, and fear of eliminating on the toilet. ${ }^{2-4}$ If defecation training is unsuccessful, alternative procedures are needed for optimizing the client's situation.

For toilet training, if no abnormalities in medical findings are observed, applied behavior analysis is often used. Especially for defecation, training has not been established because the number of instructions for establishing defecation habits is limited; thus, parent-mediated training is usually required with a risk of parental feasibility. A few case studies have been published on defecation training for individuals with ASD through face-to-face consultation. In Table 1, for

Corresponding author: Masahiko Inoue, M.Ed. masahiko-inoue@tottori-u.ac.jp

Received 2021 March 10

Accepted 2021 December 6

Online published 2022 January 4

Abbreviation: ASD, autism spectrum disorder general defecation training implemented by Sutherland et al. ${ }^{5}$ and Ito, ${ }^{6}$ a precursor assessment is conducted in advance to understand the precursor response of defecation indicated by the client, and when a precursor response is observed, the client is guided to the toilet and seated on the toilet bowl and then reinforced if defecation is performed in the toilet bowl. Few alternative intervention options are available for individual optimization if the general procedure does not result in the intended objective.

Recently, the number of consultations using internet devices for remote support has increased..$^{7-9}$ For defecation training, parent-mediated intervention through teleconsultation is helpful. Teleconsultation is attractive because it reduces the time and physical costs associated with movement. However, teleconsultation alone makes understanding the characteristics of the client and optimizing procedures difficult. According to our review of the literature, one study has investigated toilet training via teleconsultation, ${ }^{8}$ but process data from the case study of defecation training has not been published yet.

In this study, we described a case involving parentmediated defecation training consulted by the first author for a boy with ASD who began to avoid defecation training in previous interventions and became sensitive to parental reactions in a remote setting by email. As a result of behavioral assessment, the program centered on a gradual target setting and differential reinforcement was implemented to establish in-bowl defecation by his mother. This study is valuable in two respects: (1) defecation training through teleconsultation and (2) presentation of the process of examining alternative options for optimizing procedures.

\section{PATIENT REPORT}

The client in this case study was a Caucasian 5-yearold boy with ASD, who lived in Greece. The client's family comprised his father, his mother, and the client. His father was a Greek national, and his mother was a Japanese national. Although his father wanted to play a supportive role in his son's care, he was often unable to execute the mother's instructions. His mother was a university graduate, and she was implementing a 
Table 1. Comparison between general procedure and procedure in this case

\begin{tabular}{|c|c|c|}
\hline & General defecation training & Procedure in this case \\
\hline Precursor & Identified in advance & $\begin{array}{l}\text { Because his precursor was rarely observed, in order for him to demonstrate his } \\
\text { precursors of defecation, the consultee made him defecate without guiding him } \\
\text { to the toilet room even if he showed his precursors }\end{array}$ \\
\hline Guidance & Guiding when precursor is observed & Guiding when precursor is observed \\
\hline Target & $\begin{array}{l}\text { Defecation only in a specific place } \\
\text { (ex. In-bowl) }\end{array}$ & Gradually shifting the target \\
\hline $\begin{array}{l}\text { Differential } \\
\text { reinforcement }\end{array}$ & $\begin{array}{l}\text { Success: reinforcement } \\
\text { Failure: extinction }\end{array}$ & $\begin{array}{l}\text { Value-based differential reinforcement } \\
\text { Success: high-valued reinforcement } \\
\text { Failure: low-valued reinforcement }\end{array}$ \\
\hline
\end{tabular}

home-based program based on parent training by a foreign agent. Most of this case study was conducted by his mother as the consultee. The first author was the consultant of this case. The first author was educated in behavior therapy at graduate school and had 15 years of experience as a behavior therapy specialist at the time of the experiment.

The client had expressed approximately 15 words by the age of 1.5 years, which subsequently disappeared. Additionally, his parents started to notice developmental deviations. He was diagnosed with ASD at the age of 2 years and 9 months. He had severe intellectual disability, no history of epilepsy, and no medication. Due to severe intellectual disability, he was nonverbal and communicated with picture cards. The consultant implemented early behavioral intervention for two months while his family stayed in Japan. At the age of 3 years, he started to receive intensive early behavioral intervention through a foreign agent because the family moved abroad.

Regarding toilet training, behavioral therapy was introduced because no medical findings for defecation or urination were observed. The client's urination training was implemented based on the instructions of the foreign agent. In-bowl urination was increased by using a basic rapid toilet training program, and request training with the picture cards was implemented. Although urination progressed, defecation behavior did not progress naturally. In advance, general defecation training, as well as using an enema, scheduling sitting with re-guidance, and washing the client's buttocks with cold water after accidents, were implemented based on the instructions of the foreign agent. However, these procedures were not effective. At that time, the consultee communicated with the consultant and started the consultation on the client's defecation training.

\section{Intervention}

Figure 1 presents a sketch of the environment around the toilet room at home. Teleconsultation through email was conducted four times (Table 2). The timing of the four consultations is presented below the $\mathrm{X}$ axis in Fig. 2. The timing of consultations was not determined in advance; when the consultant received the email from the consultee, the consultation was conducted. The number of email exchanges and the consultation content of each consultation are presented in Table 2. This intervention comprised four phases: Phase I, II, and III and the follow-up. The target and procedure of each phase are presented in Table 3 .

The consultee used a recording sheet created by the foreign agent since the time of urination training. The recording sheet asked the user to assess four items to determine success or failure in urination and defecation at hourly intervals. Regarding bowel movements, a check mark was placed in the "success" column when defecation occurred in the toilet bowl and in the "failure" column when defecation occurred in a place other than in the toilet bowl. If extra-bowl defecation in the toilet room occurred, "ex" was written next to the check in the failure column. If success or failure in defecation occurred multiple times within the same interval, the frequency of the checks was placed in the column. Thereafter, for each data point, the number of occurrences for each week was used as the dependent variable. The consultant did not view the recording sheet until the training was completed, but the consultant received an approximate progress report from the consultee.

In \#1, according to information from the consultee, the consultee and consultant implemented a behavioral assessment on the client's defecation behaviors. Next, the consultant proposed the intervention plan (Table 1). Although the client's urination was stable, in-bowl defecation was rare. He did not request to void and rejected defecating in the toilet room and bowl. His observed precursors were rarely checked, and defecation without his precursors increased even if his parents monitored 


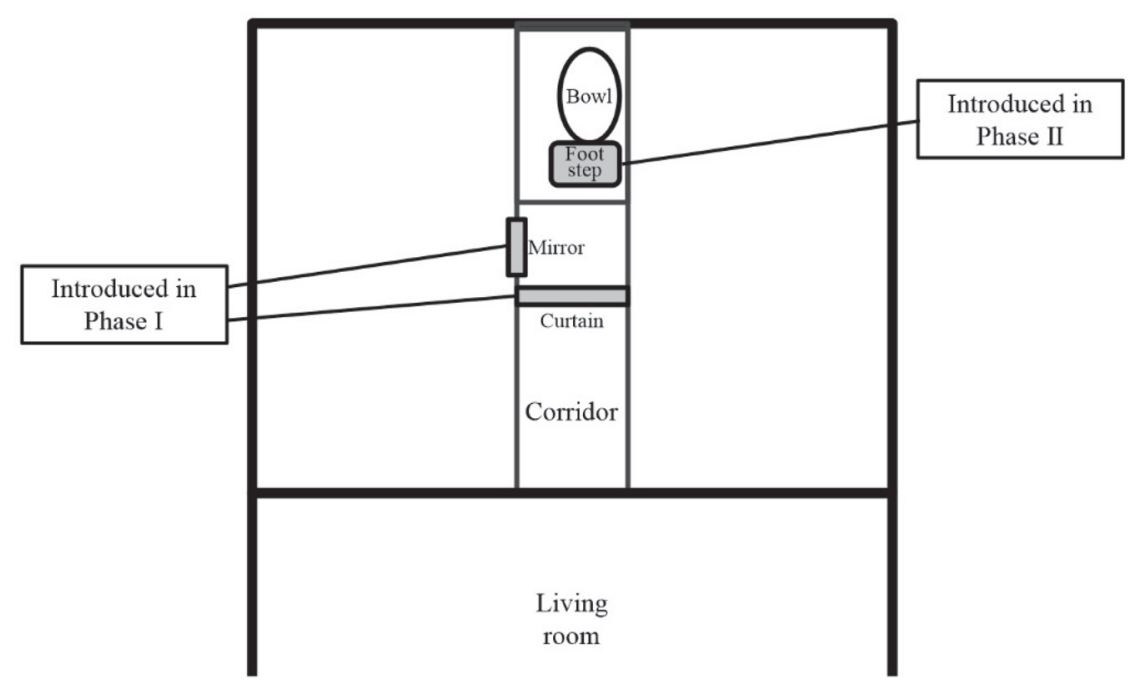

Fig. 1. Environment around the toilet room at the participant's house.

Table 2. Number of email exchanges and the consultation content at each consultation

\begin{tabular}{lll}
\hline & The number of email exchanges & Content \\
\hline$\# 1$ & $\begin{array}{l}\text { Consultant: } 6 \text { emails } \\
\text { Consultee: } 7 \text { emails }\end{array}$ & $\begin{array}{l}\text { Progress report thus far } \\
\text { Current assessment } \\
\text { Intervention procedure planning of Phase I }\end{array}$ \\
$\# 2$ & $\begin{array}{l}\text { Consultant: } 2 \text { emails } \\
\text { Consultee: } 2 \text { emails }\end{array}$ & $\begin{array}{l}\text { Progress report of Phase I } \\
\text { Intervention procedure planning of Phase II }\end{array}$ \\
\#3 & $\begin{array}{l}\text { Consultant: } 3 \text { emails } \\
\text { Consultee: } 3 \text { emails }\end{array}$ & $\begin{array}{l}\text { Progress report of Phase II } \\
\text { Intervention procedure planning of Phase III }\end{array}$ \\
& $\begin{array}{l}\text { Consultant: } 2 \text { emails } \\
\text { Consultee: } 2 \text { emails }\end{array}$ & Progress report of Phase III \\
\hline
\end{tabular}

him. He did not demonstrate signs of constipation and defecated a few times a day. He put on underwear other than during bedtime since the beginning of his urination training. Although the final target was to defecate in the toilet bowl at home, the first target was to express his precursors for the assumption. First, regarding his precursors of defecation, predicting on the basis of prior training, the frequent guidance to the toilet seemed to reduce the number of precursors and increase the number of defecation failures without precursors. It is possible that, as a result of the prior negative procedure, avoidance behavior of defecating without precursors had occurred. Therefore, to have him demonstrate his precursors of defecation, the consultee made him defecate without guiding him to the toilet room even if he showed his precursors. Next, regarding his evacuation, two patterns were observed: defecation without a precursor and defecation after wrapping the curtain in the living room when the consultee did not monitor him. The antecedent factors were standing posture, wrapping the curtain in the living room, and the sensory stimuli of the underwear. If the client failed, the consultee cleaned and dressed him quietly. Only in-bowl defecation was targeted for reinforcing, and setting in-bowl defecation as the primary goal was considered difficult. Therefore, a prediction was that in-bowl defecation would eventually be established by setting the gradual steps toward in-bowl defecation. Next, interventions were conducted mainly for step-by-step goal setting and differential reinforcement. In addition, in this case, it was necessary to follow the positive procedure even if the period was long because the process of adopting the negative procedure had not succeeded. Phase I was divided into three steps to gradually shift the target (Table 3).

In $\# 2$, the consultee reported a greater number of defecation failures than successes, and a new tendency was observed: a small amount of extra-bowl defecation in the toilet room. On the basis of these observations, the consultee and the consultant modified the procedure based on the following conclusion: the criteria that 


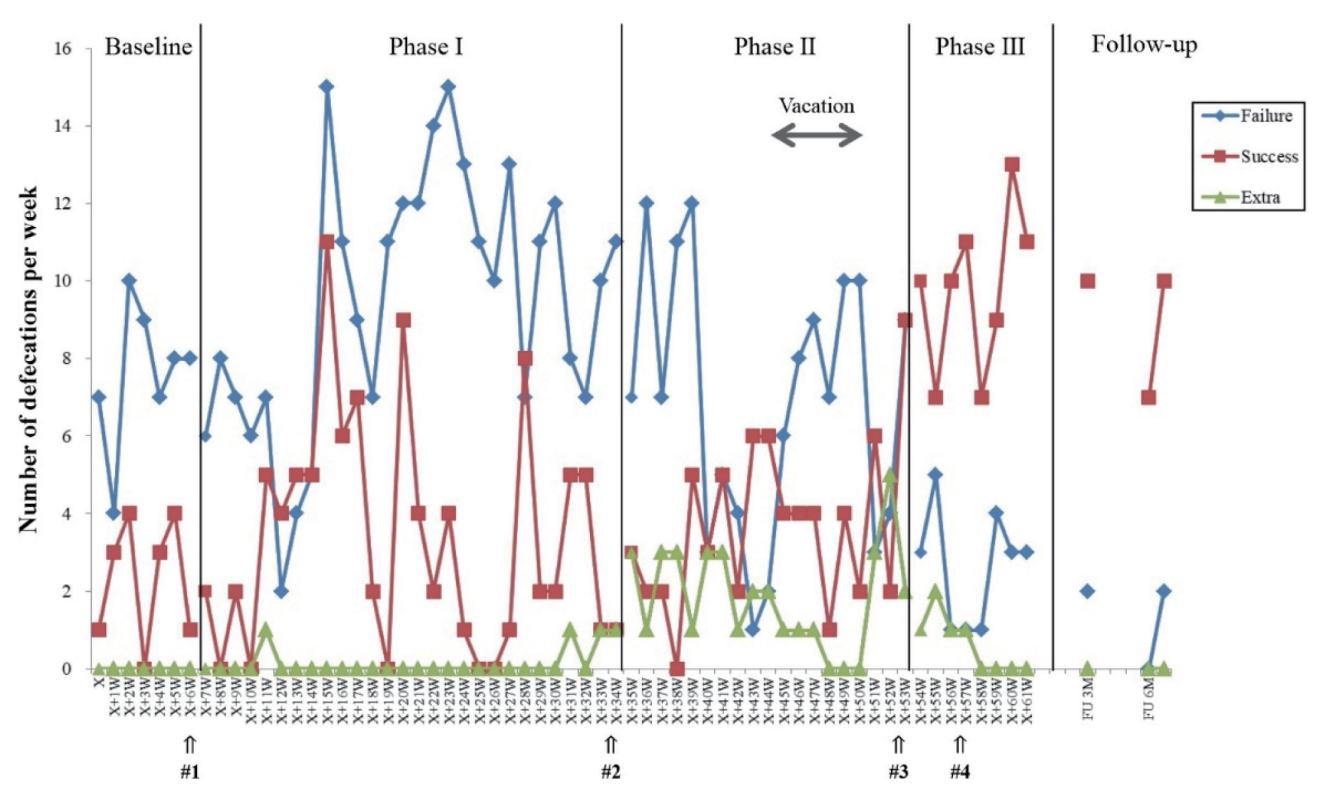

Fig. 2. Defecation behaviors of the client during baseline, intervention, and follow-up. The arrow above \#1-4 indicates when the consultation was conducted.

reinforced only in-bowl defecation might be difficult for the client. The target of Phase II was defecation in-bowl and extra-bowl in the toilet room (Table 3). Notably, priming ${ }^{10}$ (saying "Poop, you can do it in the toilet" to the client before sleep) and foot position adjustment were adopted by the consultee on the basis of information observed on the internet.

In $\# 3$, the consultee reported that the number of in-bowl defecations did not increase, the number of extra-bowl defecations increased, and the number of defecation failures decreased. Therefore, the consultee and consultant modified the procedure to reinforce only in-bowl defecation again. The target of Phase III was inbowl defecation (Table 3). The procedure used was as follows: differential reinforcement ${ }^{11}$ was implemented so that the reinforcer for in-bowl defecation was more valuable than that for extra-bowl defecation because the consultee reported in \# 2 that the client seemed to be afraid of the consultee's reaction (cleaning his buttocks and dressing him quietly) when he has defecated extrabowl in the toilet room.

In \#4, the consultee reported that the number of inbowl defecation increased. A follow- up was conducted to examine whether the defecation skill was maintained after 3 and 6 months.

Social validity is assessed to investigate the importance of the social desirability and usefulness of changes in behavior. It has encompassed a number of related areas, namely, consumer satisfaction, treatment acceptability, ecological validity, and the clinical importance of treatment outcomes. ${ }^{12}$ Social validity appraisal of this practice was implemented by the consultee. After this practice, the following five questions were asked in four laws: (1) Do you think that targeting the establishment of defecation behavior was adequate? (2) Do you think that this instructional method is adequate? (3) Are you satisfied with this practice? (4) Do you want to recommend this method to other parents? (5) Did you feel that the burden was light?

\section{Result}

The process of defecation behavior of the client is described in Fig. 2. The data on the client's precursors were not recorded, but his precursors were beginning to be observed. We observed that the number of defecation successes per week increased and that the number of defecation failures per week substantially increased. A stable increase in the number of defecation successes per week was not observed in Phase I. When Phase II started, except when life at the accommodation facility continued as usual during the vacation, a stable increase in the number of extra-bowl defecations per week was observed, and the number of defecation failures per week decreased. The number of defecation successes did not increase. When Phase III started, the number of extra-bowl defecations and defecation failures per week decreased, and the number of defecation successes per week increased. The increase in the number of defecation successes in Phase III was maintained in the follow-up after 3 and 6 months although a small number 
Table 3. Target behaviors and intervention procedure for each phase

\begin{tabular}{|c|c|c|c|}
\hline & & Target & Procedure \\
\hline \multirow[t]{3}{*}{ Phase I } & Step 1 & $\begin{array}{l}\text { Expression of precursor } \\
\text { behaviors }\end{array}$ & $\begin{array}{l}\text { Having him defecate freely without monitoring and guidance } \\
\text { Cleaning his buttocks and dressing him quietly if he was mistaken }\end{array}$ \\
\hline & Step 2 & Staying in the toilet room & $\begin{array}{l}\text { Naturally reinforcing staying in the corridor by setting the mirror and the curtain in the } \\
\text { corridor } \\
\text { Reinforcing staying in the toilet room by watching through a video }\end{array}$ \\
\hline & Step 3 & In-bowl defecation & $\begin{array}{l}\text { Guiding him to the toilet bowl if he expressed precursor behaviors } \\
\text { Re-guiding after } 5 \text { minutes if he didn't defecate } \\
\text { Reinforcing in-bowl defecation by using an exercise ball and watching TV } \\
\text { Cleaning his buttocks and dressing him quietly if he defecated other than in the toilet } \\
\text { bowl }\end{array}$ \\
\hline Phase II & & $\begin{array}{l}\text { Defecation in-bowl and } \\
\text { extra-bowl in the toilet } \\
\text { room }\end{array}$ & $\begin{array}{l}\text { Priming before sleep } \\
\text { Guiding him to the toilet bowl if he expressed precursor behaviors } \\
\text { Putting his feet on the foot step and letting him sit on the toilet bowl } \\
\text { Re-guiding while showing him the iPad after } 5 \text { minutes if he didn't defecate and reinforc- } \\
\text { ing sitting on the toilet bowl by video watching on the iPad } \\
\text { Reinforcing defecation in-bowl and extra-bowl in the toilet room by social praise and lift- } \\
\text { ing him high up in the air } \\
\text { Cleaning his buttocks and dressing him quietly if he defecated other than in the toilet } \\
\text { bowl and the toilet room }\end{array}$ \\
\hline $\begin{array}{l}\text { Phase } \\
\text { III }\end{array}$ & & In-bowl defecation & $\begin{array}{l}\text { Guiding him to the toilet bowl if he expressed precursor behaviors } \\
\text { Reinforcing extra-bowl defecation by social praise } \\
\text { Reinforcing in-bowl defecation by social praise with a smile, hugs, and playing in bed } \\
\text { Cleaning his buttocks and dressing him quietly if he defecated other than in the toilet } \\
\text { bowl and the toilet room }\end{array}$ \\
\hline
\end{tabular}

of defecation failures were observed. Additionally, although the client usually had bowel movements with the assistance of the consultee, the client had succeeded in defecation at home even during Phase III, with the assistance of his father and a home therapist. Similarly, in Phase III, the client was successful in defecating when he was under the charge of multiple therapists at the foreign agent's facility. After the end of Phase III, spontaneous defecation success was observed at the hotel.

In the social validity appraisal of this case, the consultee reported "strongly agree" in response to all items. The consultee said, "Setting the mirror and the curtain and differential reinforcement with differences in reinforcers were especially good."

\section{DISCUSSION}

In this case, as a result of implementing the teleconsultation with email for the defecation training, the number of defecation successes finally increased, although some defecation failures were observed. In Phase I, the number of defecation successes was not stable, and the number of defecation failures increased significantly. Therefore, in Phase II, extra-bowl defecation in the toilet room was also reinforced. Consequently, the number of extra-bowl defecations in the toilet room increased, and the number of defecation failures decreased. Furthermore, in Phase III, reinforcers for defecation success were more valuable than those for extra-bowl defecation in the toilet room to shift the stable extrabowl defecation in the toilet room to defecation success. As a result of differential reinforcement, the number of extra-bowl defecations decreased and the number of defecation successes increased stably. Stable defecation success was maintained at follow- up after 3 and 6 months, and generalization of caregivers and the excretion place was observed.

The results of this case indicate that defecation training via teleconsultation is feasible. Additionally, especially in the case of parent-mediated toilet- training, implementing positive procedures is essential. ${ }^{13}$ The procedure, namely gradual target setting and differential reinforcement, used in this case may provide a new option for defecation training.

Generally, differential reinforcement was performed by selectively using extinction and reinforcement. In Phase II of this case, defecation in-bowl and extra-bowl in the toilet room was reinforced, and the probability of defecation in-bowl remained low. Here, a procedure for reinforcing only in-bowl defecation as in Step 3 of Phase I can be considered, but it is considered that the probability of failure may increase if extinction 
was used for extra-bowl defecation. Therefore, the differential reinforcement used in Phase III was performed by making a difference in the value of the reinforcer without using extinction. Cividini-Motta and Ahearn implemented a special differential reinforcement. ${ }^{11}$ The authors presented the autistic youngsters with a highvalue reinforcer for responding without prompting toward types of behavior where they relied on prompting by their therapists, and a moderate-value reinforcer for responding with prompting. Consequently, they reported that the response without prompting increased. The procedure of Phase III used in this case was applying the same procedure in defecation training, similar to the differential reinforcement that distinguished between high-value reinforcement and moderate-value reinforcement as in Cividini-Motta and Ahearn. However, in this case, a reinforcement assessment was not conducted in advance, and the degree of reinforcement value was left to the parents' discretion.

The results of the social validation appraisal from the consultee were satisfactory. Teleconsultation may have contributed to decreasing the burden on the consultee to implement defecation training. The success of this intervention largely depended on the competence of the consultee (e.g., reporting the client's state during defecation training). The report of the consultee contributed to modifying and optimizing the procedure. In addition, being in charge of the early intervention in advance and understanding the characteristics of the client seem to contribute to the success of this intervention. However, the intervention contents need to be improved because the intervention period was 1 year or longer. If we could set up a session and report data frequently, the intervention period might have been halved.

There may be some possible limitations in this study. This case has major flaws with regard to parental treatment fidelity and record objectivity. In addition, when choosing teleconsultation, parental knowledge and skills regarding applied behavior analysis should be considered because these aspects also affect training. Future research can clarify the factors that promote training effectiveness.

In conclusion, we described a case involving parent-mediated defecation training for a boy with ASD who began to avoid defecation training in previous interventions and became sensitive to parental reactions through teleconsultation via email. As a result of the intervention, in-bowl defecations increased at home, which included the gradual target setting and differential reinforcement. This case emphasizes the effectiveness of gradual target setting and differential reinforcement as alternative options for optimizing procedures, as well as the possibility of toilet training via teleconsulting.

Acknowledgments: We are grateful to the client's family and Dr. Pelios ("Dynamai" Partner and Clinical Director of Autism Services) for permission to publish this case.

The authors declare no conflict of interest.

\section{REFERENCES}

1 Dalrymple NJ, Ruble LA. Toilet training and behaviors of people with autism: parent views. J Autism Dev Disord. 1992;22:265-75. DOI: 10.1007/BF01058155, PMID: 1624408

2 Lancioni GE, O'Reilly MF, Basili G. Treating encopresis in people with intellectual disabilities: A literature review. J Appl Res Intellect Disabil. 2001;14:47-63. DOI: 10.1046/ j.1468-3148.2001.00058.x

3 Peeters B, Noens I, Philips EM, Kuppens S, Benninga MA. Autism spectrum disorders in children with functional defecation disorders. J Pediatr. 2013;163:873-8. DOI: 10.1016/ j.jpeds.2013.02.028, PMID: 23522863

4 Cicero FR. Toilet training success: A guide for teaching individuals with developmental disabilities. New York: Different Roads to Learning, Inc; 2012.

5 Sutherland J, Carnett A, van der Meer L, Waddington H, Bravo A, McLay L. Intensive toilet training targeting defecation for a child with Autism Spectrum Disorder. Research and Practice in Intellectual and Developmental Disabilities. 2018;5:87-97. DOI: 10.1080/23297018.2017.1360153

6 Ito $\mathrm{H}$. A case study of parent-implemented toilet training for a child with autism: targeting in-toilet defecation. The Japanese Journal of Autistic Spectrum. 2019;17:63-7. DOI: 10.32220/ japanacademyofas.17.1 63. Japanese.

7 Schieltz KM, Wacker DP. Functional assessment and function-based treatment delivered via telehealth: A brief summary. J Appl Behav Anal. 2020;53:1242-58. DOI: 10.1002/ jaba.742, PMID: 32643811

8 Little L, Wallisch A, Dunn W, Tomchek S. A telehealth intervention to increase toilet training in autism. Am J Occup Ther. 2020;74(4_Supplement_1):7411520511p1. DOI: 10.5014/ ajot.2020.74S1-RP401E

9 Matsuoka K. The result of behavioral consultation on spitting behavior by a child with autism enrolled in special needs school. Bulletin of the Faculty of Education. Yamaguchi University. 2010;60:301-7. Japanese.

10 Bainbridge N, Smith Myles B. The use of priming to introduce toilet training to a child with autism. Focus Autism Other Dev Disabl. 1999;14:106-9. DOI: 10.1177/108835769901400206

11 Cividini-Motta C, Ahearn WH. Effects of two variations of differential reinforcement on prompt dependency. J Appl Behav Anal. 2013;46:640-50. DOI: 10.1002/jaba.67, PMID: 24114226

12 Kennedy $\mathrm{CH}$. Trends in the measurement of social validity. Behav Anal. 1992;15:147-56. DOI: 10.1007/BF03392597, PMID: 22478125

13 Issenman RM, Filmer RB, Gorski PA. A review of bowel and bladder control development in children: how gastrointestinal and urologic conditions relate to problems in toilet training. Pediatrics. 1999;103(suppl 3):1346-52. DOI: 10.1542/peds.103. S3.1346, PMID: 10353952 